\title{
Sanciones por violación al régimen de competencia: cuantificación y valoración*
}

\author{
Moderador: Camilo ERnesto Ossa BOCANeGra ${ }^{1}$ \\ PANELISTAS: CARLOS PABLO MÁRQUEZ ESCOBAR ${ }^{2}$ \\ Hugo Alberto Marín HeRnÁndez ${ }^{3}$
}

* En el evento de la referencia este panel contó con la participación de los doctores Carlos Pablo Márquez Escobar y Hugo Alberto Marín Hernández bajo la moderación del doctor Camilo Ossa Bocanegra. La elaboración del presente artículo corresponde a las ideas recogidas de lo discutido en el segmento correspondiente por los doctores Ossa Bocanegra y Marín Hernández.

DOI: https://doi.org/10.18601/01236458.n54.09

1 Camilo Ossa Bocanegra. Abogado, de la Universidad Externado de Colombia, especialista en Derecho Público de la misma universidad. Curso en Law and Economics de la Universidad de Harvard, en Cambridge, Massachusetts. Magíster en Análisis Económico del Derecho y las Políticas Públicas de la Universidad de Salamanca, España. Ganador en dos ocasiones de la mención de honor del Concurso Nacional de Derecho Económico José Ignacio de Márquez, como autor de los artículos: "Tratamiento de la colusión en la contratación pública: una visión del caso colombiano" y "Análisis Económico de las Sanciones Administrativas en el Derecho de la Competencia y del Consumo". Investigador y Docente del Departamento de Derecho Económico de la Universidad Externado de Colombia en temas de Análisis Económico del Derecho de la Competencia y la Regulación. Cargo actual: Personero Municipal de Ibagué.

2 Carlos Pablo Márquez Escobar. PhD, estudió Derecho, Filosofía y una Maestría en Economía de la Universidad Javeriana, y obtuvo un LL.M. en la Universidad de Harvard y un doctorado en Derecho de la competencia, de la Universidad de Oxford. Fue director de la Comisión de Regulación de Comunicaciones de Colombia entre octubre 2012 y noviembre 2014, y Comisionado de noviembre de 2014 a febrero de 2015. Previamente, fue Superintendente de Defensa de la Competencia de la Autoridad de la Competencia de Colombia. Se especializa en Derecho de la competencia, Derecho corporativo, regulación de servicios de comunicaciones, y en general regulación económica, y tiene una gran experiencia en los procedimientos de carteles, abuso de posición dominante, integraciones empresariales, competencia desleal y otros procedimientos en Derecho administrativo, donde ha conocido más de doscientos casos en materia de protección de la competencia y promovió más de 40 proyectos regulatorios en materia de telecomunicaciones. En su experiencia como director de la CRC y como Superintendente de la SIC tuvo la oportunidad de estudiar múltiples sectores de la economía, desde el sector agrícola, pasando por el sector financiero, minero, retail, telecomunicaciones y salud, entre otros. Además, tiene más de quince años de experiencia en la enseñanza del Derecho, el diseño de cursos de formación para una amplia variedad de orígenes e intereses y el desarrollo de programas de cumplimiento en materia regulatoria. También ha sido conferencista en universidades como Columbia, Harvard, Oxford y organizaciones internacionales, como la OCDE, la UNCTAD y la UIT, entre otras. Ha sido reconocido por Who is Who Legal como uno de los Future Leaders in Antitrust, el Global Competition Review como uno de los mejores abogados del mundo menores de 40 años y por la Revista Dinero, en Colombia, como uno de los 40 líderes menores de 40 en Colombia. 


\section{INTRODUCCIÓN}

\section{Camilo Ossa Bocanegra}

Cuando hablamos de Derecho de la competencia, necesariamente tenemos que referirnos a dos objetivos claves de la ley. Por un lado, el netamente jurídico, que busca promover la libertad económica, la libertad de empresa, el mantenimiento de la eficiencia en los mercados y la protección de los consumidores, como un mandato derivado del artículo 333 de la Constitución Política, que posteriormente fue reforzado vía legal.

Por otro lado, encontramos el objetivo económico que busca la maximización del bienestar del consumidor a través de la eficiencia económica, que consagra una función de represión, castigo y sanción con el objetivo de mantener la libre competencia económica en nuestro país.

Así, encontramos que la Constitución Política de Colombia, en los artículos 332 y siguientes, establece el marco desde el cual debe dirigirse la actividad económica como un presupuesto fundamental del Estado Social de Derecho; el mismo artículo $334^{[4]}$ de la Constitución establece que será el Estado, como encargado de la dirección general de la economía, el que deba intervenir, en asuntos que impliquen la restauración de actividades que, por algún factor externo -que bien podrían ser los señalados en el

Ha sido listado en Chambers and Partners (Rising Stars) y Legal 500 como Recommended Lawyer en el área de competencia, telecomunicaciones y propiedad intelectual. Ha ganado varios premios, como el Premio Robert Cooter en Derecho y Economía, la Beca Banco de la República y la Medalla al Mérito de las Comunicaciones del Gobierno de Colombia. Cuenta con cuatro libros en materia de Derecho económico y más de veinte artículos académicos en materia de Derecho y Economía. Habla con fluidez español e inglés. Además, es dibujante y pintor aficionado.

3 Hugo Alberto Marín Hernández. Abogado, de la Universidad Externado de Colombia ${ }_{i}$ especialista en Derecho Público de la misma Universidad ${ }_{i}$ Doctor en Derecho summa cum laude por la Universidad Carlos III de Madrid. Se ha desempeñado como asesor jurídico de diversas entidades estatales; Magistrado Auxiliar del Consejo de Estado; profesor de los Departamentos de Derecho Administrativo, Derecho Constitucional, Derecho Procesal, Derecho Civil y Derecho Laboral de la Universidad Externado de Colombia, en donde inició su actividad docente desde el año 1998. Actualmente se desempeña como docente e investigador de tiempo completo en la Universidad Externado de Colombia, consultor en temas de Derecho Público y Conjuez de la Sección Segunda del Consejo de Estado. Autor de diversas publicaciones en el ámbito del Derecho Administrativo y del Derecho Constitucional, entre ellas los libros Discrecionalidad administrativa y El principio de proporcionalidad en el Derecho Administrativo colombiano, publicados por esta Casa de Estudios, además de un significativo número de artículos en libros y revistas tanto nacionales como extranjeras.

4 El artículo 334 de la Constitución Política señala: "La dirección general de la economía estará a cargo del Estado. Este intervendrá, por mandato de la ley, en la explotación de los recursos naturales, en el uso del suelo, en la producción, distribución, utilización y consumo de los bienes, y en los servicios públicos y privados, para racionalizar la economía con el fin de conseguir en el plano nacional y territorial, en un marco de sostenibilidad fiscal, el mejoramiento de la calidad de vida de los habitantes, la distribución equitativa de las oportunidades y los beneficios del desarrollo y la preservación de un ambiente sano. Dicho marco de sostenibilidad fiscal deberá fungir como instrumento para alcanzar de manera progresiva los objetivos del Estado Social de Derecho. En cualquier caso, el gasto público social será prioritario" (destacado fuera del original). 
Decreto 2153 de 1992 o en la Ley 1340 de 2009-, se comporta de manera ineficiente, teniendo la obligación de garantizar la actividad económica y la libre competencia.

Tanto el artículo 333 como el 334 habilitan al Estado para que intervenga, bien sea desde una perspectiva ex ante -regulación económica- o a través de una óptica ex post-referida al Derecho de la competencia propiamente dicho-. Aquí podríamos decir que la sanción cumple un papel, desde el punto de vista jurídico, de reproche; sin embargo, debemos decir que los presupuestos están dados para que dicho juicio también sea económico-, de todo aquel comportamiento que atente de forma directa o indirecta el normal desarrollo del mercado y la economía en general, afectando sus parámetros de eficiencia, pero también afectando a los demás competidores y, en consecuencia, a los consumidores.

Este panel trata justamente de estos aspectos: los reproches, tanto jurídicos como económicos, que se hacen a un comportamiento que, previamente, la ley ha catalogado como ilegal, que bien podría tratarse, hablando de libre competencia económica, de acuerdos, actos, abuso de posición dominante y el régimen de integraciones empresariales.

El régimen sancionatorio por prácticas contrarias a libre competencia lo encontramos en los artículos 25 y siguientes de la Ley 1340 de 2009, donde se establecen unas sanciones de cien mil salarios mínimos legales mensuales vigentes o el $150 \%$ del beneficio reportado con la infracción a la norma, teniendo también que decir que, en materia de integraciones empresariales, cuando se incumple la obligación de pedir autorización y dicha integración afecta la libre competencia en un mercado determinado, se puede ordenar la reversión de la operación de integración. Existe otro tipo de sanciones que debemos mencionar, como es el caso de los remedios estructurales y comportamentales, referidos a instrumentos usados para remover elementos que distorsionan las condiciones de competencia del mercado, en el caso de los estructurales y, para el caso de los comportamentales, son medidas que afectan la conducta específica de la empresa y conllevan imponer restricciones de carácter prohibitivo - no bacer- o impositivo - bacer-.

Para desarrollar el presente panel, hemos propuesto tres ejes temáticos: i) Análisis económico de las sanciones, ii) La sanción como elemento indemnizatorio y iii) Disuasión de la sanción -Prevención general positiva- Experiencia comparada en Estados Unidos y Europa.

\section{ANÁLISIS ECONÓMICO DE LAS SANCIONES}

¿Es eficiente el modelo sancionatorio de la Ley 1340 de 2009 en cuanto al castigo de la conducta y la disuasión del comportamiento? Evolución de la aplicación de la sanción por parte de la SIC en los últimos 10 años. Análisis con metodología de teoría económica. 


\section{Camilo Ossa}

El Análisis Económico del Derecho se encarga de estudiar el Derecho, como objeto, con metodología de teoría económica. Partiendo de este supuesto podemos encontrar que la escuela clásica o Escuela de Chicago es la que más aportes le ha dado al Derecho de la competencia, en el sentido de buscar, en el cumplimiento de lo señalado por el artículo 333 de la Constitución Política, generar estados eficientes, reglas o normas que generen estos estados. Siendo así, uno de los papeles principales que cumplen las sanciones, es el de prevención general frente a los demás competidores y frente al mismo sancionado.

Ya sabemos que, según el artículo 333 de la Constitución Política, hay que garantizar la libre competencia, y la mejor manera para lograrlo es que exista eficiencia en los mercados, menor intervención del Estado y que sea el mismo mercado el que se autorregule y el que dicte las propias normas mediante las cuales se van a desenvolver las relaciones entre competidores, bien sea verticales u horizontales.

Lo que buscamos es eficiencia, ese es el parámetro de medición según el Análisis Económico del Derecho aplicado al Derecho de la competencia, y ¿qué puede ocurrir? Que podemos encontrar que existen comportamientos ineficientes y, según la escuela clásica del AED, los individuos somos bomo economicus, es decir, racionales, egoístas y maximizadores, en sede de competencia, de sus utilidades.

Bajo esa lógica de la racionalidad, si, por ejemplo, a nosotros como consumidores nos suben el precio de un producto vamos a buscar un sustituto que nos genere el mismo bienestar; con las sanciones sucede algo similar: estas funcionan como precios, lo que quiere decir que, a mayor sanción, menos demanda de la conducta prohibida y en consecuencia obtengo eficiencia. Si miramos el artículo 25 de la Ley 1340 de 2009, vamos a encontrar que las sanciones, por una práctica contraria a la libre competencia, pueden ser de cien mil salarios mínimos legales mensuales o el 150\% del beneficio reportado con la infracción a la norma, sanciones que, en principio, parten de esa lógica de generar disuasión -lograr que se demande menos del comportamiento prohibidoaumentando los montos sancionatorios.

Dicho lo anterior, hay que advertir una cuestión del modelo de sanción de las prácticas anticompetitivas en la ley colombiana, para lo cual utilizaremos el siguiente modelo a modo ejemplificativo ${ }^{5}$ :

Utilizaremos un juego en el cual las empresas $\left(\operatorname{Em}_{1}\right.$ y $\left.\operatorname{Em}_{2}\right)$ tienen diferentes opciones ante la posibilidad de celebrar o no un acuerdo anticompetitivo. Entonces, dos empresarios ${ }^{6}$

5 Ossa Bocanegra, Camilo (2014). "La colusión en la contratación pública: una visión del caso colombiano", en Revista de Derecho n. ${ }^{\circ} 42$, p. 246.

6 En el ejemplo trataremos el caso de dos empresarios, bajo la modalidad de acuerdo, pero entiéndase que las prácticas anticompetitivas se pueden realizar también de manera unilateral, como en el caso de los actos y el abuso de posición dominante. 
que compiten en un mercado tienen la opción de cartelizarse o no cartelizarse; si deciden no cartelizar es porque individualmente cada uno observa que la utilidad esperada podría ser mayor que el beneficio que podrían obtener con la cartelización. Si, por el contrario, deciden cartelizar es porque la utilidad individual esperada es menor que el beneficio que podrían obtener con la no cartelización y, por ende, el beneficio reportado con el acuerdo (cartelización) es mayor que la posible sanción a imponer en caso de ser detectados y posteriormente sancionados. Igualmente, si deciden esta opción de cartelizar, hay que tener en cuenta que el artículo 14 de la Ley 1340 de 2009 dispone los beneficios a los que puede acceder quien colabore en la detección de prácticas anticompetitivas, con lo cual el comportamiento de quienes participan en un acuerdo anticompetitivo puede variar de conformidad con la estrategia que adopten los demás.

Es decir, desde una visión clásica del Análisis Económico del Derecho, si para el empresario celebrar un acuerdo es más beneficioso que la multa a la cual puede ser expuesto, multiplicado por la probabilidad de que la autoridad lo detecte y lo sancione, el empresario, desde su racionalidad económica -como bomo economicus- tenderá hacia la cartelización.

De ahí la importancia de establecer montos sancionatorios relevantes, pero también hay que tener en cuenta un factor fundamental y es el relacionado con la eficacia de la autoridad encargada de detectar los comportamientos prohibidos y de aplicar la ley. En una sanción óptima, "se debe escoger una combinación de probabilidad y severidad del castigo que imponga ese costo al potencial infractor de la norma, en este caso, de competencia. Por ejemplo: Un costo esperado del castigo de $\$ 1.000$ puede imponerse combinando una multa de $\$ 1.000$ con una probabilidad de aprehensión y de condena de 1 . Una multa de $\$ 10.000$ con una probabilidad de 0,1 , y así sucesivamente ${ }^{7 "}$. Es decir, entre más baja la probabilidad de detección y sanción, más alta debe ser la multa a imponer.

\section{LA SANCIÓN COMO ELEMENTO INDEMNIZATORIO}

¿Es posible bablar en Colombia de indemnización de perjuicios, vía proceso administrativo sancionador, por una práctica contraria a la libre competencia? ¿Sí? ¿No? ¿Opciones?

Hugo Marín

Con el propósito de responder a este interrogante se reflexionó sobre la naturaleza jurídica del procedimiento administrativo sancionatorio como expresión del ius puniendi del Estado, con el propósito de examinar su compatibilidad con la posibilidad de abrir

7 Posner, Richard (2002). El análisis económico del Derecho, México, Fondo de Cultura Económica, México, p. 352 . 
espacio a la alternativa de procurar y eventualmente obtener indemnizaciones de perjuicios en el marco de actuaciones administrativas de esta índole.

Se recordó, entonces, que la jurisprudencia y la doctrina, de manera prácticamente pacífica y bastante uniforme, tanto en el contexto colombiano como en el comparado, destacan que la potestad sancionatoria de la Administración Pública entronca en los clásicos conceptos de poder y de función de policía, entendidos como facultades del Estado consistentes en la adopción de decisiones de alcance general -poder de policíao de carácter particular -función de policía- que restringen o condicionan el ejercicio de sus derechos por parte de las personas, con el propósito de salvaguardar el interés general o el orden público.

Se ha destacado, en ese orden de ideas, la finalidad marcadamente preventiva, ejemplarizante o educativa de la potestad sancionatoria de la Administración, pero al propio tiempo complementaria de las actividades reglamentarias, autorizatorias, prohibitivas, fiscalizadoras, de inspección o control, entre otras, que se asignan a las autoridades administrativas, en la medida en que su ius puniendi propende por la eficacia en el ejercicio de aquellas otras tareas o actividades asignadas a la Administración. Constitucionalmente el ius puniendi administrativo se apoya, además de la función intervencionista que al Estado se asigna en el modelo Social de Derecho -artículo 1 constitucional-, en el deber de obediencia al ordenamiento jurídico que se impone a todos los coasociados desde los artículos 4, 6 y 95 de la Carta Política.

Por lo demás, se ha recalcado también que la función punitiva encomendada a la Administración debe estar signada por su propósito represivo o de restricción de derechos que se impone a una persona como reacción frente a un comportamiento ilícito por su parte, de manera que la actuación administrativa y la decisión correspondiente tendrán naturaleza sancionatoria no solo si buscan constreñir al cumplimiento de un deber jurídico o al restablecimiento de la legalidad conculcada por quien contraría el orden jurídico al realizar una determinada actividad, sino que contarán con esa connotación punitiva si, además de lo anterior o en exclusiva, el perjuicio que le irrogan al administrado tiene un sentido retributivo, que se traduce en la irrogación de un mal añadido al que de por sí implica el cumplimiento forzoso de una obligación que ya se debía o la imposibilidad de continuar desarrollando una actividad a la cual no se tenía derecho; ha de tratarse, pues, de un perjuicio añadido con el cual se afecta al infractor en el acervo de bienes jurídicos de los cuales disfrutaba lícitamente.

En el anterior orden de ideas, resulta evidente que la indemnización de perjuicios es una finalidad claramente ajena a los propósitos que animan al Derecho administrativo sancionatorio; de hecho y en línea con lo anterior, el diseño que se ha realizado del procedimiento administrativo sancionatorio tanto en la Ley 1340 de 2009 como en la Ley 1437 de 2011 -CPACA-, en nuestro sentir, en modo alguno consideró la posibilidad de que en el marco de tales actuaciones administrativas la autoridad competente 
se ocupara de estudiar solicitudes y adoptar decisiones atinentes a la indemnización de perjuicios. Para que ello fuese posible, en nuestra opinión, dado que las autoridades públicas desde el punto de vista de las competencias que ejercen, se encuentran rigurosamente sometidas al principio de legalidad y solo pueden desplegar aquellas actividades o funciones que les han sido expresamente conferidas normativamente, en el actual marco jurídico no estarían investidas de la atribución de pronunciarse, al instruir y decidir procedimientos sancionatorios, sobre cuestiones relacionadas con indemnización de perjuicios. Ello no quiere decir que resulte inconveniente o desaconsejable que el ordenamiento jurídico prevea a futuro la posibilidad de facultar a la Administración para que aborde, en el marco de actuaciones sancionatorias, tal suerte de asuntos.

\section{Camilo Ossa}

Desde la óptica del ordenamiento jurídico colombiano, como garantía derivada del artículo 333 de la Constitución Política, corresponde al Estado garantizar la libre competencia en los sectores de la economía nacional y que conmine a los agentes que participan en un mercado determinado a respetar las reglas, principios y derechos que orientan la actuación empresarial. Con ello, la posibilidad de exigir a estos sujetos el cumplimiento de los fines propuestos con el establecimiento del llamado derecho de la competencia con la "amenaza" de que, ante el incumplimiento, pueden ser sujetos de sanción por los efectos adversos que puedan generar con su actuación.

Sin embargo, no solo es importante adecuar la protección de la libre competencia con lo ordenado por la Constitución Política, sino, también, revisar el ámbito de protección legal de la norma o, en este caso, de las normas que en su conjunto conforman el régimen jurídico de protección de la libre competencia, y el fundamento, tanto jurídico como económico, que sustentan la actuación administrativa para proteger la eficiencia de los mercados, la libertad de empresa, la libertad económica y los derechos de los consumidores.

Sobre este punto solo quiero hacer referencia, en el sentido de que, en Colombia, no es posible obtener una indemnización de perjuicios vía proceso administrativo sancionador, lo que también se ha conocido como aplicación privada del Derecho de la competencia. Sin embargo, también debemos anotar que, en otros regímenes jurídicos como el europeo, existe la aplicación privada del Derecho de la competencia, que es el realizado por jueces y tribunales que pertenecen a la jurisdicción civil ordinaria.

La posibilidad que se encuentra abierta en Colombia, y es poco explorada, está relacionada con la posibilidad de interponer una acción de grupo por prácticas contrarias a la libre competencia, siendo este un interés colectivo consagrado en el artículo 88 de la Constitución Política, reglamentado en la Ley 472 de 1998. 


\section{DISUASIÓN DE LA SANCIÓN -PREVENCIÓN GENERAL POSITIVA- EXPERIENCIA COMPARADA EN ESTADOS UNIDOS Y EUROPA}

¿Cuál es el rol que debe jugar el principio de proporcionalidad tanto en la dosimetría punitiva concreta frente a la decisión de actuaciones sancionatorias puntuales, como en la adopción de medidas legislativas atinentes a la previsión de topes y/o de parámetros para la fijación de las sanciones en esta materia?

Hugo Marín

Se expuso cuál es la razón de ser, el fundamento constitucional de la obligatoriedad para la Administración y la utilidad que reporta en el ejercicio de funciones administrativas, el principio de proporcionalidad como herramienta de construcción y de justificación de las decisiones que las autoridades administrativas adoptan en ámbitos en los cuales disponen de márgenes de apreciación discrecional que es, precisamente, el margen con el cual cuentan al acometer la labor de dosimetría punitiva. En ese orden de ideas, se reseñó cómo el principio de proporcionalidad resulta de forzosa utilización en el marco del procedimiento administrativo sancionatorio comoquiera que en su seno debe desatarse la colisión entre principios que se plantea entre la intensidad de la afectación a los derechos e intereses del administrado que va a ser sancionado, de un lado y, de otro, las funciones que está llamada a cumplir la punición administrativa -retribución, eficacia de la función administrativa y disuasión, ejemplarización o prevención general, ya mencionadas-.

En ese marco, se reflexionó sobre el rigor metodológico con el cual la Superintendencia de Sociedades ha hecho uso de los tres mandatos parciales que incorpora el juicio de proporcionalidad-adecuación, necesidad y ponderación o proporcionalidad strictu sensu- en algunos casos que en su momento tuvieron significativa resonancia y se debatió sobre la idoneidad del diseño normativamente previsto en la Ley 1340 de 2009 en cuanto a los parámetros allí fijados para la cuantificación de las sanciones, algunos de los cuales parecieran quedarse cortos para lograr esa finalidad de prevención general mencionada al paso que otros podrían dar de sí, juiciosamente aplicados con apego al principio de proporcionalidad, lo suficiente como para lograr el citado cometido.

Camilo Ossa

Quisiera traer a colación la sanción impuesta a Telefónica de España por una conducta conocida como compresión de márgenes, tesis esbozada por la Comisión Europea y posteriormente ratificada por el Tribunal Europeo; dicha conducta, consistente, según estas autoridades europeas, en "una compresión abusiva de márgenes cuando la diferencia entre las tarifas minoristas de una empresa dominante y las tarifas mayoristas para servicios comparables que aplica a sus competidores es negativa o insuficiente para 
cubrir los costes específicos de producto incurridos por el operador dominante en la prestación de sus propios servicios minoristas en el mercado descendente" 8 .

Existen tres casos emblemáticos en la Unión Europea relacionados con la compresión de márgenes: i) Deutsche Telekom, ii) TeliaSonera y iii) Telefónica, los cuales constituyen el insumo de lo que es la compresión de márgenes, sus elementos, los efectos que generan en el mercado y la potencialidad restrictiva de la libre competencia; sin embargo, en punto a la sanción, que es el tema que nos convoca hoy día, aun cuando los efectos en el mercado son muy similares, existe una diferencia entre el caso Deutsche Telekom y Telefónica, en el primero de los cuales imponen una sanción de 12,6 millones de euros, mientras en el segundo la sanción es de 140 millones de euros.

La diferencia puede estar relacionada con dos elementos clave: el primero, en cuanto al daño ocasionado al mercado y el segundo, en un claro intento de enviar un mensaje a los demás competidores en el mercado previniendo la comisión de este tipo de prácticas, lo que podríamos considerar como una prevención general positiva.

Y, por último, no puedo dejar pasar la oportunidad para señalar una cuestión clave en materia de prevención general, una tesis más teórica que práctica, pues aún no se ha puesto en funcionamiento en Colombia y es una que esbocé en un artículo que escribí hace algunos años titulado "Análisis económico de las sanciones administrativas en el Derecho de la competencia y el consumo": manifesté que "existen mecanismos que ayudan, aun cuando el monto sancionatorio sea 'pequeño', a cumplir con la función general preventiva de la que ya hemos hecho alusión, generando el mismo efecto que puede producir echar mano de un régimen diferente dadas las 'bondades' de su sanción"9.

Se habló en dicho artículo de los daños punitivos, dándoles tratamiento de daños compensatorios para lograr su aplicación en el ordenamiento jurídico colombiano, como herramienta para lograr una prevención general eficiente de los comportamientos considerados contrarios a la libre competencia económica.

Sobre los cuales - daños compensatorios- podemos decir que en materia de sanciones administrativas tiene la puerta abierta para su aplicación, o por lo menos de lo que se entiende de ella, dado que "si la política pública que justifica el daño punitivo en el sistema anglosajón es la de regular conductas mediante las sanciones económicas, en nuestro sistema son muchos los mecanismos que para tal efecto se tienen, verbigracia, las sanciones administrativas que puede imponer el Estado a las personas naturales o jurídicas. Dicha sanción, que buscaría el mismo objetivo que el daño punitivo, sería a

8 Decisión 2003/707/CE del 21 de mayo de 2003, en un procedimiento con arreglo al artículo 82 del Tratado CE (Asunto COMP/C-1/37.451, 37.578, 37.579 — Deutsche Telekom AG) (texto pertinente a efectos del EEE.) [notificada con el número C (2003) 1536]. Diario Oficial n. ${ }^{\circ}$ L 263 de 14/10/2003 pp. 0009-0041.

9 Ossa Bocanegra, Camilo (2015). "Análisis ecónomico de las sanciones administrativas en el Derecho de la competencia y el consumo", en Revista Derecho del Estado, n. ${ }^{\circ} 35$, pp. 151-179. 
favor de quien sufre el daño, es decir, de la sociedad en su conjunto, sin que implique el enriquecimiento de una persona a nombre de aquella"10.

Si miramos la filosofía del daño punitivo, encontramos que el mismo, desde una visión económica, puede definirse de la siguiente manera: "[Se otorgan] daños punitivos [bajo la denominación que se quiera dar], cuando el comportamiento del demandado [la empresa] es malicioso, opresivo, grosero, caprichoso, fraudulento"11.

Para lograr esto, se puede echar mano de la regla de $\mathrm{Hand}^{12}$, entendida como:

En un sistema de responsabilidad subjetiva, si el costo en precaución (B) es menor al valor de daño $(L)$ multiplicado por la probabilidad de ocurrencia del hecho $(P)$, la empresa se supone negligente y debe pagar.

Dicha regla busca recuperar la eficiencia perdida con una sanción artificialmente baja, incentivando, en este caso a los competidores, a invertir más en precaución, por

10 Henao Pérez, Juan C. (1998). El daño. Análisis comparativo de la responsabilidad extracontractual del Estado en Derecho colombiano y fránces. Universidad Externado de Colombia, Bogotá, p. 48.

11 Cooter, Robert \& Ulen, Thomas (2004). Law \& Economics. Pearson Addison Wesley, Boston, p. 372.

12 "Caso United States Vs. Carrol Towing. El caso se inició con motivo de la pérdida de una barcaza y su carga en el puerto de Nueva York. Un conjunto de buques estaba amarrado-mediante una única línea de cuerdas- a los muelles de ese puerto cuando la empresa propietaria de uno de ellos contrató a la demandada (una empresa de remolque marítimo) a fin de moverla fuera del área de los muelles. El buque en cuestión se encontraba sin tripulación a bordo, por lo cual los dependientes de la empresa de remolque procedieron, por su cuenta, a liberarlo y reajustar toda la línea de cuerdas que lo amarraba. Esa operación se realizó de modo inadecuado y una de las barcazas, movida por el viento y la marea, rompió su amarre, chocó contra otro buque y se hundió con su carga.

El propietario del buque hundido demandó a la empresa de remolcadores por la negligencia de sus trabajadores en la operación. La demandada, a su vez, replicó que el demandante fue también negligente porque ningún agente de su empresa estaba a bordo de la barcaza en el momento en que la tripulación del remolcador debía manipular los cabos. Si se hubiera contado con la presencia de un agente capacitado - sostuvo la demandada- la operación podría haberse realizado correctamente. El magistrado entendió que no había ninguna norma especial que determinara si era o no obligatorio que hubiera un agente de la empresa actora en su barcaza en esas condiciones y, por ello, solo quedaba por establecer si esa ausencia era o no culpable según las normas generales, y que la decisión sobre ese punto definiría la cuestión.

El juez Learned Hand sostuvo al respecto:

(...) la obligación del propietario de adoptar medidas contra los daños resultantes es una función de tres variables: (I) la probabilidad de que la barcaza se suelte de su amarre ${ }_{i}(2)$ la gravedad del daño resultante, si ello ocurre $;$ (3) el costo de adoptar las precauciones adecuadas. Posiblemente sea conveniente expresar esta noción en términos algebraicos: si denominamos $P$ a la probabi$\operatorname{lidad}_{i} L$ al daño; y $B$ al costo de adoptar las medidas de precaución, la responsabilidad depende de que $B$ sea menor que $L$ multiplicada por $P$, esto es si $B<P L$ (esa acción será culpable) (...).

En el caso, concluyó que la omisión de la actora, que dejó amarrada su barcaza sin personal a bordo en esas condiciones, debía considerarse, en efecto, culpable. Esta formulación resulta, por cierto, sorprendente. Cuando se intenta comprender qué es y cuándo se verifica la culpa, desde la perspectiva jurídica tradicional se habla de estándares, como omisión de diligencias que exige la naturaleza de la obligación o comparaciones como el bonus paterfamiliae o buen comerciante, que la solución propuesta por el juez Hand se expresa como "hay culpa cuando lo invertido en prevención es menor a los daños esperados dejan muchas dudas en situaciones concretas que se alejan de los extremos" Ibíd, p.1.073. 
cuanto una exoneración de responsabilidad va a estar atado a lo que se invierta en precaución multiplicado por el valor del daño y la probabilidad de ocurrencia del mismo, lo que en estructura puede generar un efecto de disuasión de los comportamientos prohibidos por la ley.

En conclusión, y enlazando el porqué de los daños punitivos -o compensatorios- es porque en un sistema de responsabilidad subjetiva, la función que cumplen estos daños es recuperar la ineficiencia creada por el menor valor pagado por $(L)$, haciendo que en todo caso el competidor pague $(L)$ de manera plena, lo que incentiva inversiones óptimas -competidor bueno- en $(B)$ hasta que se iguale a $(P L)$, lo que denota en eficiencia ${ }^{13}$.

\section{CONCLUSIONES}

Quedan elementos bastante importantes que deben comenzar a estudiarse y analizarse con más detalle, específicamente por parte de la autoridad de competencia, como es el relacionado con el Análisis Económico del Derecho y su impacto en cuanto al diseño de reglas que puedan conducir a estados eficientes y, claro está, la importancia creciente en el establecimiento de una política sancionatoria que permita, en un análisis costo-beneficio, generar incentivos para el respeto de la norma y, en consecuencia, del derecho que nos asiste a todos, tanto competidores como consumidores.

De otro lado, la indemnización de perjuicios es una finalidad claramente ajena a los propósitos que animan al Derecho administrativo sancionatorio; de hecho, el diseño que se ha realizado del procedimiento administrativo sancionatorio tanto en la Ley 1340 de 2009 como en la Ley 1437 de 2011, de ninguna manera consideró la posibilidad de lograr este cometido indemnizatorio en los procesos administrativos sancionatorios. Ahora bien, esto no quiere decir que resulte inconveniente que el ordenamiento jurídico considere a futuro la posibilidad de facultar a la Administración para que, en el marco de actuaciones sancionatorias, trate este tipo de peticiones.

La experiencia internacional nos arroja muchas luces sobre los avances doctrinarios y jurisprudenciales en torno a una defensa de la competencia, así como de una política seria en la imposición de sanciones. Casos como el de Telefónica de España, aquí enunciado, y otros, como el de Microsoft por abuso de posición dominante, donde además de la sanción pecuniaria, se le impuso medidas correctivas, pueden ser bastante cuestionables en torno a la información que debo brindar a mis competidores.

Pero también podemos remontarnos a experiencias judiciales novedosas en su momento, como fue la propuesta por el juez norteamericano Learned Hand para generar incentivos, que, si bien fue diseñada y aplicada inicialmente a un caso de responsabilidad civil, también puede ser adecuada para un caso de responsabilidad administrativa con el fin único de logar disuasión de comportamientos castigados por la ley. de la competencia y el consumo", en Revista Derecho del Estado. n. ${ }^{\circ} 35$, pp. 171 y 172. 
No se puede dejar de lado el principio de proporcionalidad y la importancia y el desarrollo tan importante que ha tenido, lo que ha permitido llegar a ser una herramienta de construcción y de justificación de las decisiones que las autoridades administrativas adoptan, sobre todo cuando la discrecionalidad está presente. Es definitiva su utilización y aplicación, dado el choque de principios que se pueden dar en un proceso administrativo sancionador, máxime en relación con las funciones que está llamada a cumplir la sanción administrativa, en punto a la retribución, eficacia y disuasión.

\section{REFERENCIAS}

Cooter, Robert \& Ulen, Thomas (2004). Law \& Economics. Pearson Addison Wesley, Boston, p. 372.

Henao PéreZ, Juan C. (1998). El daño. Análisis comparativo de la responsabilidad extracontractual del Estado en derecho colombiano y fránces. Universidad Externado de Colombia, Bogotá, p. 48.

OSSA BoCANeGra, CAMILO (2014). "La colusión en la contratación pública: una visión del caso colombiano", en Revista de Derecho n. ${ }^{\circ} 42$, p. 246.

Posner, Richard (2002). El análisis económico del Derecho, México, Fondo de Cultura Económica, México, p. 352.

Ossa Bocanegra, CAmilo (2015). "Análisis ecónomico de las sanciones administrativas en el derecho de la competencia y el consumo", en Revista Derecho del Estado. n. ${ }^{\circ} 35$, pp. 171 y 172. 